\title{
Altered expression patterns of lipid metabolism genes in an animal model of HCV core-related, nonobese, modest hepatic steatosis Ming-Ling Chang*1, Chau-Ting Yeh1, Jeng-Chang Chen ${ }^{2}$, Chau- Chun Huang ${ }^{3}$, Shi-Ming Lin ${ }^{1}$, I-Shyan Sheen ${ }^{1}$, Dar-In Tai ${ }^{1}$, Chia-Ming Chu ${ }^{1}$, Wei-Pin Lin ${ }^{1}$, Ming-Yu Chang ${ }^{4}$, Chun-Kai Liang ${ }^{1}$, Cheng-Tang Chiu ${ }^{1}$ and Deng-Yn Lin ${ }^{1}$
}

\author{
Address: ${ }^{1}$ Liver Research Center and Department of Hepatogastroenterology, Chang Gung Memorial Hospital, No 5, Fu Hsing Street, Kuei Shan \\ Taoyuan, Taiwan; Chang Gung University, College of Medicine, Taoyuan, Taiwan, ²Department of Surgery, Chang Gung Memorial Hospital, \\ Taoyuan, Taiwan, ${ }^{3}$ Division of Endocrinology \& Metabolism, Department of Internal Medicine, Chang Gung Memorial Hospital, Taipei, Taiwan \\ and ${ }^{4}$ Division of Pediatric Critical Care and Emergency Medicine, Chang Gung Memorial Hospital, Taoyuan, Taiwan \\ Email: Ming-Ling Chang* - mlchang8210@gmail.com; Chau-Ting Yeh - chauting@adm.cgmh.org.tw; Jeng-Chang Chen - jengchang@so- \\ net.net.tw; Chau-Chun Huang - hcc.hcc99@msa.hinet.net; Shi-Ming Lin - Ismpaicyto@adm.cgmh.org.tw; I- \\ Shyan Sheen - issheen.jks@msa.hinet.net; Dar-In Tai - tai48978@adm.cgmh.org.tw; Chia-Ming Chu - chu0066@cgmh.org.tw; Wei- \\ Pin Lin - weipin@cgmh.org.tw; Ming-Yu Chang - mlchang8210@gmail.com; Chun-Kai Liang - mlchang8210@gamil.com; Cheng- \\ Tang Chiu - ctchiu@adm.cgmh.org.tw; Deng-Yn Lin - lindy0043@adm.cgmh.org.tw \\ * Corresponding author
}

Published: 29 February 2008

BMC Genomics 2008, 9:109 doi:10.1186/1471-2164-9-109
Received: 2 November 2007

Accepted: 29 February 2008

This article is available from: http://www.biomedcentral.com/147I-2/64/9/109

(C) 2008 Chang et al; licensee BioMed Central Ltd.

This is an Open Access article distributed under the terms of the Creative Commons Attribution License (http://creativecommons.org/licenses/by/2.0), which permits unrestricted use, distribution, and reproduction in any medium, provided the original work is properly cited.

\begin{abstract}
Background: Because the gene expression patterns of nonobese hepatic steatosis in affected patients remain unclear, we sought to explore these patterns using an animal model of nonobese hepatic steatosis.

Methods: We developed mice that conditionally express the hepatitis $\mathrm{C}$ virus (HCV) core protein regulated by the tetracycline transactivator (tTA). Microarray analyses and reverse-transcription polymerase chain reaction were performed using liver samples of both the double transgenic mice (DTM), which express both the HCV core and tTA, and single transgenic mice (STM), which express tTA alone, at 2 months of age. Functional categories of genes with altered expression were classified using gene ontology programs. Serum glucose, lipid levels, and systemic blood pressure were also measured.
\end{abstract}

Results: Approximately $20-30 \%$ of hepatocytes from the DTM were steatotic. No significant differences were observed in the serum glucose, lipid content, or blood pressure levels between the DTM and STM. Gene expression analyses revealed Sterol-regulatory element-binding protein (SREBP) pathway activation and dysregulation of the following genes involved in lipid metabolism: 3-hydroxy-3-methylglutarylcoenzyme A synthase I, Apolipoprotein All, Apolipoprotein Cl, acyl-CoA thioesterase I, and fatty acid binding protein I; in mitochondrial function: solute carrier family 25 member 25 and cytochrome $c$ oxidase subunit II; in immune reaction: complement component 3, lymphocyte antigen 6 complex, locus A, lymphocyte antigen 6 complex, locus C, lymphocyte antigen 6 complex, locus D, and lymphocyte antigen 6 complex, locus $\mathrm{E}$.

Conclusion: Some genes of lipid metabolism, mitochondrial function, and immune reaction and the SREBP pathway are involved in HCV core-related, nonobese, modest hepatic steatosis. 


\section{Background}

Nonalcoholic fatty liver disease (NAFLD) can be a severe, progressive liver disease leading to the development of cirrhosis [1]. Obesity and type 2 diabetes are well-known risk factors for the development of NAFLD. However, NAFLD is not rare in nonobese adults. The result of examining over 700 nonobese individuals older than 30 years with NAFLD who participated in medical examinations shows that NAFLD can be considered an early predictor of metabolic disorders for the normal-weight population [2]. Nevertheless, the basis for nonobese hepatic steatosis remains uncertain, particularly for those who lack any metabolic syndromes. Several experimental animal models for nonobese NAFLD have been proposed. Among them, cholesterol-fed rabbits share several physiopathological features of NAFLD, like hyperlipidemia, but are devoid of insulin resistance or obesity [3]; while overexpression of SREBP-1a in spontaneously hypertensive rat models were nonobese animals with hypertension, hepatic steatosis, and the metabolic syndrome [4]. All the above models are associated with metabolic syndrome in various degrees. Whether the basis of the "uncomplicated" nonobese hepatic steatosis is similar to hepatic steatosis complicated by obesity and/or metabolic syndrome remains unresolved. Hepatic steatosis is present in almost $50 \%$ of patients infected by hepatitis C virus (HCV), which therefore suggests it is an important contributor to NAFLD [5]. We aimed to study the gene expression involved in lipid metabolism of an animal model of nonobese hepatic steatosis free from metabolic syndrome based on the conditional HCV core transgenic mice developed from our previous work. Liver from the 2 month old conditional HCV core transgenic mice on chow without doxycycline (dox) showed that the severity of hepatic steatosis correlated with HCV core expression, peaked at the age of 2 months but diminished gradually [6].

\section{Results}

\section{Fatty liver evaluation}

For the double transgenic mice (DTM), which express both the HCV core and tetracycline transactivator (tTA), oil red stain documented the existence of hepatic lipid vesicles that were compatible with HCV core protein in the parallel sections (Figure 1B and 1D). The severity of hepatic steatosis correlated with HCV core expression, and peaked at the age of 2 months, when the hepatic steatosis was microvesicular (Figure $2 \mathrm{~A}$ and $2 \mathrm{~B}$, arrows). As the mouse aged, the microvesicular steatosis was replaced by macrovesicular steatosis (in a lesser degree, Figure 2C, arrows) and dimished gradually (Figure 2D). The proportions of steatotic hepatocytes were approximately 20$30 \%$ in the liver of 2 month old mice on chow without dox, which were examined under low power field for $\mathrm{H}$ and E stain (Figure 2A).

\section{Serum glucose, lipid, insulin and homeostatic model assessment for insulin resistance (HOMA-IR) evaluation} No significant differences in the serum glucose, lipid, insulin, or HOMA-IR levels between the DTM and single transgenic mice (STM), which express tTA alone, were noted. No definitive abnormal levels were found in any of the mice.

\section{Systemic blood pressure (SBP) measurement}

There was no significant difference in the SBP level between the DTM and STM. No definitive abnormal levels were found in any of the mice.

\section{Microarray analyses}

A total of 20871 genes were evaluated. Of these, 97\% remained after filtering for missing data and/or low expression levels. Significance Analysis of Microarrays (SAM) revealed no sex bias in gene expression from the microarray data. For all of the 6 pairs, there were 28 genes that had $M$ values (ie, $\log 2 \mathrm{Cy} 5 / \mathrm{Cy} 3) \geq 1$, and 26 genes that had $M$ values $\leq-1$. Among the 28 up-regulated genes, those involved in lipid metabolism were as follows: serum amyloid A1 (Saa1), serum amyloid 3 (Saa3), 7-dehydrocholesterol reductase (Dhcr7) and 3-hydroxy-3-methylglutaryl-coenzyme A synthase 1 (HMGCS1). Among the 26 down-regulated genes, those involved in lipid metabolism were as follows: apolipprotein CI (Apo CI), apolipoprotein AII (Apo AII), Fatty acid binding protein 1, liver (FABP1), acyl-CoA thioesterase I (Acot1)and apolipoprotein $\mathrm{E}$ (Apo E) [see Additional file 1]. Gene functional analysis for the microarray data showed that only the acute-phase response had a significant $P$ value and false discovery rate (FDR) (Table 1).

\section{Quantitative real-time polymerase chain reaction (Q-RT- PCR)}

Our Q-RT-PCR data were regarded as significant at M (ie, $\log 2$ Experiment/control for Q-RT-PCR) $\geq 0.6$ or $\leq-0.6$. For the four up-regulated genes involved in lipid metabolism, Q-RT-PCR of all the 6 pairs showed only HMGCS1 had $M$ value higher than 0.6; for the five down-regulated genes involved in lipid metabolism, Apo CI, Apo AII, Acot1 and $F A B P l$ showed $M$ values less than -0.6. The mean and standard deviation of $M$ values of Q-RT-PCR for the various genes are listed in Table 2.

\section{Pathway classification}

ArrayXPath identified 5 out of 79 input elements in 9 out of 277 BioCarta pathways. The pathways are shown in Table 3. Among the 9 pathways, 7 pathways showed significance with both P-values and Q-values less than 0.05. The Sterol-regulatory element-binding protein (SREBP) pathway composed of SREBF1, SREBF2, MBPTS1, SCAP, LDLR and HMGCS1 is involved in lipid metabolism. HMGCS1 activation was identified in the current study. 

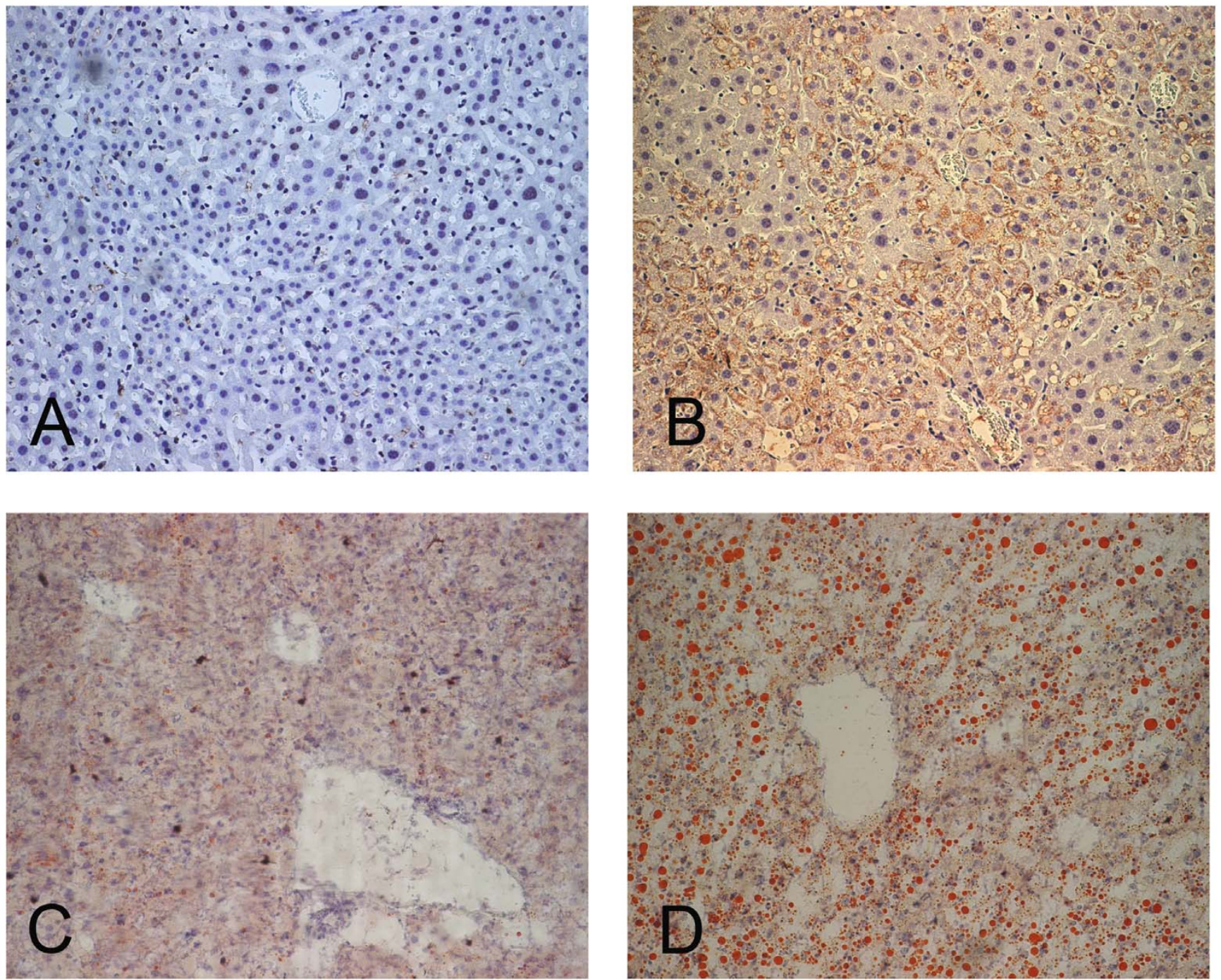

Figure I

Immunostaining of HCV core protein in STM (A, 20x) and DTM (B, 20x) livers fixed in 4\% PFA, and the corresponding Oil Red $O$ stain for fat in the livers of the frozen section (C, 20x; D, 20x). The livers were from the mice at the age of 2 months old.

Table I: Gene functional analysis for selected genes from microarray analyses

\begin{tabular}{|c|c|c|c|c|c|c|}
\hline Category & Genes in Category & $\begin{array}{c}\text { Genes in } \\
\text { category (\%) }\end{array}$ & $\begin{array}{l}\text { Genes in list in } \\
\text { category }\end{array}$ & $\begin{array}{l}\text { Genes in list in } \\
\text { category (\%) }\end{array}$ & $P$-value ${ }^{\dagger}$ & FDR_P $\neq$ \\
\hline \multicolumn{7}{|l|}{ Biological Process } \\
\hline $\begin{array}{l}\text { GO:6953: acute-phase } \\
\text { response }\end{array}$ & 19 & 0.189 & 3 & 17.65 & 0.0000 & $<.0001$ \\
\hline $\begin{array}{l}\text { GO:50896: response to } \\
\text { stimulus }\end{array}$ & 1910 & 19.01 & 8 & 47.06 & 0.0080 & 0.0637 \\
\hline \multicolumn{7}{|l|}{ Molecular Function } \\
\hline $\begin{array}{l}\text { GO:52 I5: transporter } \\
\text { activity }\end{array}$ & 1163 & 9.927 & 5 & 33.33 & 0.0123 & 0.1353 \\
\hline
\end{tabular}

tStudent's t-test.

$\ddagger$ Adjusted P-value for Benjamini and Hochberg method FDR. 

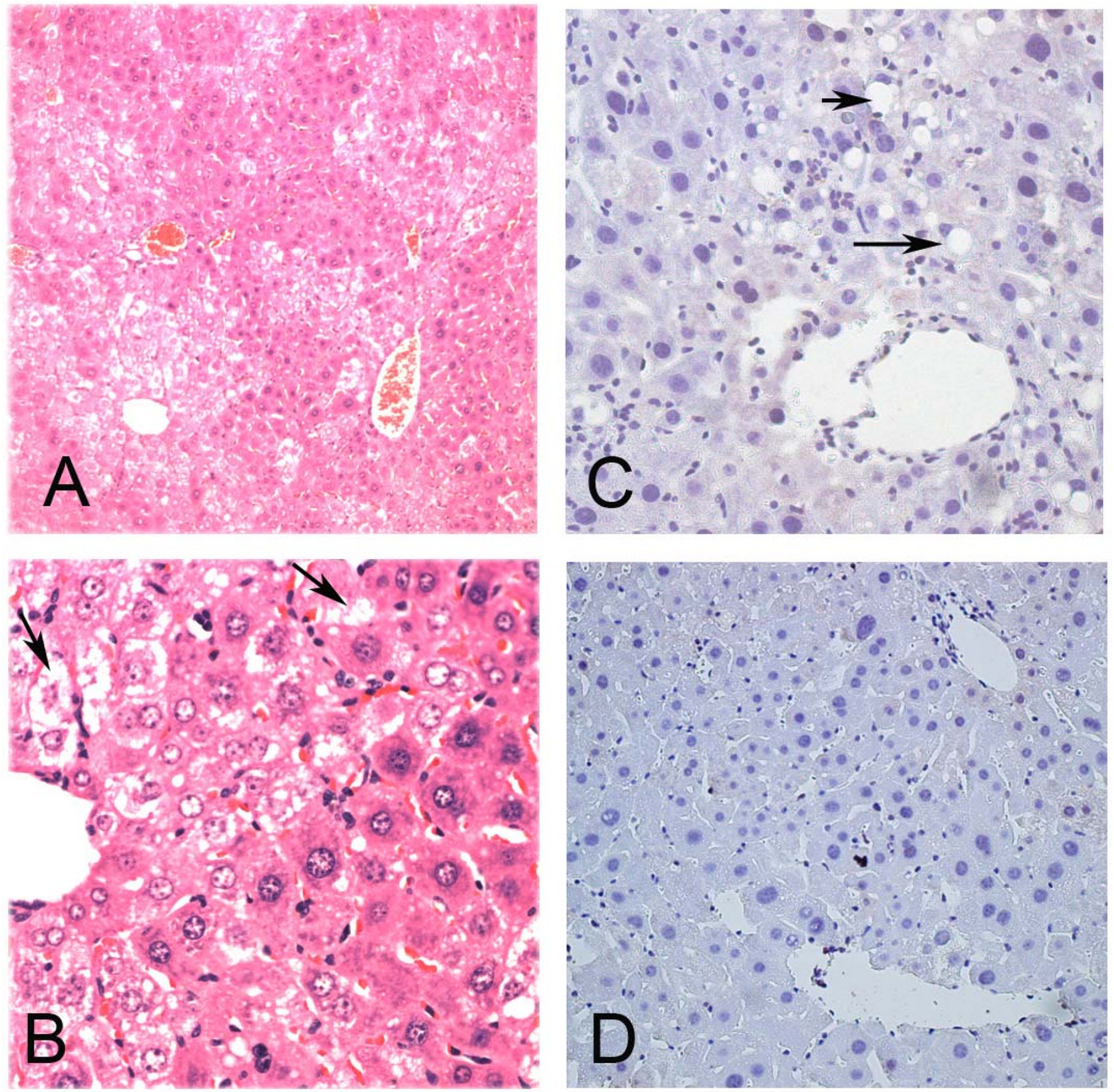

\section{Figure 2}

$H$ and $E$ stain of DTM livers at 2 months (A, 20x; B, 40x); 4 months (C, 40x); and 6 mo of age (D, $40 x$ ). The whitish areas (fatty area) intermixed with reddish areas was observed in the low power field $(A)$. The characteristic microvesicular steatosis is denoted by arrows under high power field (B).

Table 2: List of the mean and standard deviation of M values for Q-RT-PCR for genes involved in lipid metabolism.

\begin{tabular}{llllllllll}
\hline Gene name & Saal & Saa3 & HMGCSI & Dhcr7 & ApoE & ApoCl & ApoAll & FABPI & AcotI \\
\hline Mean +/- & $0.35+/-$ & $0.67+/-$ & $2.58+/-$ & $0.78+/-$ & $0.02+/-$ & $-2.05+/-$ & $-1.98+/-$ & $-1.77+/-$ & $-2.12+/-$ \\
SD & 0.67 & 1.13 & 1.01 & 1.52 & 0.49 & 1.12 & 0.58 & 0.62 & 1.20 \\
\hline
\end{tabular}


Table 3: Activated pathway identified from ArrayXpath website.

\begin{tabular}{|c|c|c|c|}
\hline pathway & Identified node & p-value & q-value \\
\hline Classical Complement Pathway & $2 / 11(60)$ & 0.0007 & 0.0036 \\
\hline Complement Pathway & $2 / 16(30)$ & 0.0015 & 0.0038 \\
\hline SREBP control of lipid synthesis & $\mathrm{I} / 6(27)$ & 0.0236 & 0.0319 \\
\hline Alternative Complement Pathway & 1/8 (43) & 0.0314 & 0.0319 \\
\hline Fibrinolysis Pathway & $\mathrm{I} / \mathrm{I}(\mathrm{I} 4)$ & 0.0430 & 0.0319 \\
\hline Double Stranded RNA Induced Gene Expression & $1 / 10(14)$ & 0.0391 & 0.0319 \\
\hline Extrinsic Prothrombin Activation Pathway & $1 / 13(24)$ & 0.0506 & 0.0329 \\
\hline Lectin Induced Complement Pathway & $1 / 10(52)$ & 0.0391 & 0.0339 \\
\hline Intrinsic Prothrombin Activation Pathway & $\mathrm{I} / 23(36)$ & 0.0881 & 0.051 \\
\hline
\end{tabular}

Identified node: matched nodes/unique nodes in pathway (redundant nodes in pathway).

\section{Discussion}

We developed an animal model of nonobese hepatic steatosis based on mice conditionally expressing the $\mathrm{HCV}$ core protein. Doxycycline (Dox) chow, which contained an analog of tetracycline, was used to regulate the transgene expression. Dox is regarded as a steatogenic drug by means of inhibiting mitochondrial fatty acid beta-oxidation [7]. To avoid the bias of drug-related hepatic steatosis, we prescribed both the DTM and STM with the same course of Dox administration. We also ensured that the hepatic steatosis was due to expression of the HCV core transgene by comparing the liver biopsies from the DTM and STM. The former did show significant hepatic steatosis compared to the latter.

HCV core protein is known to play crucial roles in host cell lipid metabolism both in vitro and in vivo [8-13]. Gene expression profiles have been reported after HCV core expression in primary hepatocytes [14], hepatoma cell lines, [15] and yeast cells [16]. However, the data obtained for hepatic steatosis in vitro might not mirror that obtained in vivo. The expression of HCV core leads to progressive hepatic steatosis in several lines of constitutive transgenic mice [17]. Hepatocellular carcinoma (HCC) also results in some of these older mice due to oxidative stress [18]. Thus, in those constitutive transgenic mice, hepatic steatosis is a relay of HCC and may be the sequel of carcinogenic gene expression. In the current model, HCV core expression was robust and paralleled the degree of hepatic steatosis. Both core expression and hepatic steatosis peaked at 2 months but diminished gradually afterward. We did not find HCC in these mice, regardless of their age, partly due to HCV core-related, augmented hepatocellular apoptosis [6]. Therefore, because we established the exact timing of peak hepatic steatosis emergence ( 2 months) and these mice did not develop HCC, we propose that this is a valid model to study the basis of hepatic steatosis without bias. None of the transgenic mice showed definitively abnormal serum glucose, lipid, insulin, or HOMA-IR levels, and the blood pressure remained normal. The gene expression profiles of nondi- abetic and diabetic ob/ob mice reported by Lan et al. suggest that increased hepatic lipogenic capacity protects the ob/ob mice from the development of type 2 diabetes [19]. Cumulatively, these observations indicate a lack of metabolic syndrome in these conditional HCV core mice that may have resulted from an only modest level of steatosis, which protects these mice from diabetes but is not sufficiently vigorous to cause metabolic syndrome.

Gene functional analysis of the microarray data showed that only the genes for an acute-phase response had significant $P$ values and FDR (Table 1). These results are compatible with the observation that HCV core expression leads to augmented oxidative stress and hepatocellular apoptosis, but not subsequent hepatic inflammation and fibrosis in DTM [6]. However, several genes involved in mitochondrial function (Slc25a25 and COX2), the immune reaction (C3, $L y 6 a, L y 6 c, L y 6 d$, and $L y 6 e$ ), coagulation $(F g b)$, the cell cycle (G0s2), cell differentiation (Onecut1 and Gadd45g), cell proliferation (Ifitm3), apoptosis (Bbc3), angiogenesis (Anxa2), and cytochrome P450 function (Cyp4a14) were also regulated in the livers of DTM (see Additional file 1). At the basis of gene expression, the data did not conclusively explain why those mice did not develop HCC. For example, the downregulation of Onecut1 and upregulation of Ifitm3 might inhibit cell proliferation $[20,21]$, whereas the downregulation of GADD45G might enhance tumor cell growth [22]. Several attempts were performed to approach the gene expression for human NAFLD. A study on microarray analyses including 62 human liver samples showed that mitochondrial alterations play a major role in the development of steatosis per se and the activation of inflammatory pathways is present at a very early stage of steatosis, even if no morphological sign of inflammation is observed [23]. In addition, the analyses of global hepatic gene expression in histologically progressive nonalcoholic steatohepatitis revealed down-regulated genes for maintaining mitochondrial function and up-regulated genes of C3 and hepatocyte-derived fibrinogen-related protein [24]. Therefore, mitochondrial function alteration and C3-impli- 
cated immune reaction/inflammation (complementary pathway activation is documented in Table 3 ) are likely to contribute at least partly to the hepatic steatosis in the current transgenic mice based on human NAFLD gene expression studies. Cyp4a enzymes were identified as initiators of oxidative stress in the liver of mice fed a methionineand choline-deficient (MCD) diet, while the role of Cyp4a14 in hepatic steatosis demands further clarification [25].

We focused our analysis of the microarray data, Q-RTPCR, and the gene nodal classifications on lipid metabolism. The livers of DTM showed one up-regulated gene, HMGCS1; four down-regulated genes, Apo CI, Apo AII, $A \cot 1$, and $\mathrm{FABPl}$; and one activated pathway, SREBPmediated control of lipid synthesis. HCV core expression decreased hepatic lipoprotein secretion and caused steatosis as shown using a line of constitutive HCV core transgenic mice [26]. By transfecting cell lines with HCV core plasmids, Barba et al. showed the colocalization of HCV core protein and Apo AII [8]. The direct binding of HCV core with Apo AII was also documented [27]. Moreover, hepatic human Apo AII expression in HCV core protein/ Apo AII $\%$ transgenic mice diminished intrahepatic core protein accumulation, whereas the converse scenario is highly possible, although uncertain, based on our result [13]. Little data directly address the relationships between HCV core-related steatosis and Apo CI. The infectivity of HCV pseudotyped retroviral particles is enhanced by Apo $C I$ [28]. This observation suggests that a correlation may exist between Apo CI and the HCV core because the HCV core protein plays an important role in infectivity.

Acot 1 is an enzyme that hydrolyzes long-chain acyl-CoAs of $C(12)-C(20)-C o A$ in chain length to the free fatty acid and coenzyme A (CoA) [29]. The potency of Acot1 may serve to modulate intracellular concentrations of acylCoAs, free fatty acids, and CoA to affect various cellular functions, including lipid metabolism [30]. The downregulation of Acot1 likely leads to increased Acyl-CoA and subsequent beta oxidation, which might counter-regulate hepatic steatosis secondary to HCV core expression [31].

In regard to the SREBP pathway, several in vivo systems have documented its association with HCV or the HCV core protein. During the early stages of acute HCV infection, chimpanzees that develop either transient or sustained clearance of virus show activated genes involved in the SREBP pathway as determined by genome-wide transcriptional analyses [32]. HCV infection is also known to induce the proteolytic cleavage and phosphorylation of SREBPs via oxidative stress [33]. Furthermore, genes related to fatty acid biosynthesis and SREBP-1c promoter activity are up-regulated by the HCV core protein in cell lines and constitutive HCV core transgenic mice livers in a
PA28gamma-dependent manner [34]. Our results demonstrate that aside from SREBPs themselves, HMGCS1, the crucial enzyme for the SREBP pathway, also plays some role in HCV core related hepatic steatosis. Whether HMGCS1 activation is specific to HCV core expression or is subsequent to hepatic steatosis demands further clarification.

To our knowledge, FABP1 has not been reported as being responsible for HCV core-related steatosis. The primary role of all the FABP family members is the regulation of fatty acid uptake and intracellular transport [35]. The FABP1 gene is turned on by long-chain fatty acids and nonmetabolized fatty acids in a physiologically relevant manner [36]. FABP1 and microsomal triglyceride transfer protein (MTP) are known to shunt fatty acids cooperatively into de novo synthesized glycerolipids and transfer lipids into very low-density lipoprotein (VLDL), respectively, which act together to maintain hepatic lipid homeostasis [37]. It is likely that either the HCV core leads to hepatic steatosis by means of modulating $F A B P l$ gene expression to inhibit MTP protein activity and VLDL secretion [38] or that downregulation of $F A B P l$ is a nonspecific phenomenon secondary to hepatic steatosis.

\section{Conclusion}

We developed an animal model of nonobese hepatic steatosis with the transgenic expression of the HCV core protein. These mice were free of metabolic syndrome. The degree of hepatic steatosis paralleled the expression of the $\mathrm{HCV}$ core protein, and both core protein expression and steatosis diminished with time. Gene expression analysis of liver RNA from the transgenic mice showed that several genes involved in lipid transport, mitochondrial function, the immune reaction, and inflammation were either upor down-regulated. The SREBP pathway was also activated as shown by the upregulation of the HMGCS1 gene. Our model lends itself to studying the gene expression patterns in nonobese hepatic steatosis, especially those associated with HCV infection.

\section{Methods \\ Transgenic mice regeneration}

Mice conditionally expressing HCV core gene were generated as described [6]. Briefly, the HCV core gene sequence was isolated by reverse-transcription RT-PCR from the plasma of a patient with chronic HCV genotype $1 \mathrm{~b}$. It was cloned into the pUGH16-3 vector, which contains the tetracycline response element [39]. Fertilized ova from FVB/ $\mathrm{N}$ mice were injected with the construct, and several founder mice were obtained. These were crossed with a second transgenic line that is homozygous for the tTA, under the control of the liver activator protein (LAP) promoter, which is hepatocyte-specific [40]. The LAP-tTA mice were generously provided by J. M. Bishop and Rong 
Wang (University of California, San Francisco, CA). Unless otherwise indicated, mating pairs were maintained on dox-containing chow (doxycycline $(200 \mathrm{mg}) / \mathrm{chow}$ (kg), Bio-serve, Frenchtown, NJ) to suppress the HCV core during development and through weaning (1 month old). At approximately 1 month of age, dox was withdrawn. The Animal Care and Use Committee at Chang Gung Memorial Medical Center approved the use of animals for this study.

\section{HCV core protein expression}

Analyses of HCV core protein expression was performed by immunohistochemical staining as described previously for the DTM and STM [6].

\section{Fatty liver evaluation}

Fat vesicles were identified by Oil Red O staining in frozen liver sections using a commercial kit (BioGenex, San Ramon, CA) according to the manufacturer's protocol. Hematoxylin and eosin ( $\mathrm{H}$ and $\mathrm{E}$ ) stains were also performed for the fatty liver grading.

\section{Serum glucose and lipid evaluation}

Tail bleedings for biochemistry data evaluation were performed in 10 DTM (5 males and 5 females) and 10 STM ( 5 males and 5 females) at 2 months of age. The assays for glucose, uric acid, triglyceride, and cholesterol (Vitros DT60 II Chemistry System, Johnson \& Johnson, Rochester, NY) were adopted for using tail blood according to the manufacturer's protocol after 12 hours of fasting.

\section{Insulin evaluation}

To determine the serum insulin levels, ELISA bioassay kits for insulin (Crystal Chem Inc., Downers Grove, IL) were adopted according to the manufacturer's protocol.

\section{HOMA-IR}

By using the formula:

glucose in $\mathrm{mg} / \mathrm{dLX} 0.05551$ Xinsulin in UIU/mL 22.5

the HOMA-IR was calculated for the fasting $\mathrm{m}$

serum.

\section{SBP}

SBP was measured in conscious mice (10 DTM and 10 STM, respectively) by tail-cuff plethysmography (Model 179 blood pressure analyzer; Hugo Sachs Elektronik, Hugstetten, Germany) as described previously [41].

\section{Microarray analyses}

Microarray analyses were used to obtain global gene expression profiles from the livers of three pairs of 2 month old female DTM versus 2 month old female STM; and three pairs of 2 month old male DTM versus 2 month old male STM. Since appropriate RNA pooling can provide equivalent power and improve the efficiency and cost-effectiveness of microarray experiments with a modest increase in the total number of subjects [42], pooled samples from three STM individuals were used as controls. Experimental procedures were carried out according to the manufacturer's protocols. Briefly, $0.5 \mu \mathrm{g}$ of total RNA was amplified by a Fluorescent Linear Amplification Kit (Agilent Technologies, Santa Clara, CA) and labeled with Cy3-CTP or Cy5-CTP (CyDye, PerkinElmer, Waltham, MA) during the in vitro transcription process. RNA from DTM was labeled with Cy5 and RNA from STM was labeled with Cy3. Cy-labeled cRNA $(2 \mu \mathrm{g})$ was fragmented to an average size of about 50-100 nucleotides by incubating with fragmentation buffer (Agilent Technologies) at $60^{\circ} \mathrm{C}$ for 30 minutes. Correspondingly, fragmented labeled cRNA was then pooled and hybridized to a mouse oligonucleotide microarray containing 20,871 unique mouse genes (Agilent Technologies) at $60^{\circ} \mathrm{C}$ for $17 \mathrm{~h}$. After washing and drying by nitrogen gun blowing, microarrays were scanned with an Agilent microarray scanner (Agilent Technologies) at $535 \mathrm{~nm}$ for Cy3 and $625 \mathrm{~nm}$ for Cy5. Scanned images were analyzed by Feature Extraction Software 8.1 (Agilent Technologies). Image analysis and normalization software was used to quantify signal-to-background intensity for each feature, substantially normalizing the data by the rank-consistency-filtering LOWESS method [43]. Sex bias analysis was performed using Significance Analysis of Microarrays (SAM) [44], and P-values of $<0.05$ were considered as statistically significant.

\section{Q-RT-PCR}

Q-RT-PCR was performed for the genes involved in lipid metabolism significantly up or down regulated in the microarray $(\log 2 \mathrm{Cy} 5 / \mathrm{Cy} 3$, ie, $M \geq 1$ or $\leq-1)$ using the same RNA isolated for microarray analysis. To prepare a cDNA pool from each RNA sample, total RNA ( $5 \mu \mathrm{g})$ was reverse transcribed using MMLV reverse transcriptase (Promega, Madison, WI), and the resulting samples were diluted 40 times by volume with nuclease-free water. Each cDNA pool was stored at $-20^{\circ} \mathrm{C}$ until further real-time PCR analysis. Real-time PCR reactions were performed on the Roche LightCycler Instrument 1.5 (Roche, Indianapolis, IN) using LightCycler ${ }^{\circledR}$ FastStart DNA Master ${ }^{\text {PLUS SYBR }}$ Green I kit (Roche) according to manufacturer's protocol. The sequences of the primers for Saa1, Saa3, HMGCS1, Dhcr7, Apo E, Apo CI, Apo AII, FABP1, and Acot1 are shown in Table 4.

\section{Pathway classification}

Only gene expression data with $M$ values $\geq 1$ or $\leq-1$ were analyzed for potential pathways. 
Table 4: Primers used for real-time PCR of genes involved in lipid metabolism.

\begin{tabular}{ll}
\hline Gene & Primer sequence \\
\hline Saal & F: 5'-GGAGACACCAGGATGAAGCTA-3' \\
& R: 5'-TAGGCTCGCCACATGTCC-3' \\
Saa3 & F: 5'-TGCTCGGGGGAACTATGAT-3' \\
& R: 5'-ACAGCCTCTCTGGCATCACT-3' \\
HMGCSI & F: 5'-CCCCTTCACAAATGACCACAG-3' \\
& R: 5'-GACAGCTGATTCAGATTCGGC-3' \\
Dhcr7 & F: 5'-TACCTAGGCTGGGGAGATTG-3' \\
& R: 5'-GGGTGGTACACCAAGTACAGG-3' \\
Apo E & F: 5'-CACGAGCGTCACTTCTTGG-3' \\
& R: 5'-CAGGAAAGGGTCCAGGTTCT-3' \\
Apo CI & F: 5'-CCTGATTGTGGTCGTAGCC-3' \\
& R: 5'-CCGGTATGCTCTCCAATGTT-3' \\
Apo All & F: 5'-CCATCTGTAGCCTGGAAGGA-3' \\
& R: 5'-GTACTGAGTGAACAGGCTCTGC-3' \\
FABPI & F: 5'-CCATGACTGGGGAAAAAGTC-3' \\
& R: 5'-GCCTTTGAAAGTTGTCACCAT-3' \\
Acotl & F: 5'-CTGGCGCATGCAGGATC-3' \\
& R: 5'-CTGGCGCATGCAGGATC-3' \\
\hline
\end{tabular}

$F$, forward primer; $R$, reverse primer.

Potential pathways that were activated in the DTM were investigated using a web-based service [45], where Fisher's exact test and the FDR followed the Storey's scheme were applied to evaluate the statistical significance.

\section{Statistical analyses}

Normalized microarray data were further filtered for missing genes and for genes with low expression levels. Considering multiple comparisons, the adjusted P-values for the Benjamini and Hochberg method FDR were also calculated for the selected genes, and an adjusted P-value of less than 0.05 was chosen for subsequent functional and pathway exploration. Analyses were accomplished using the SAS 8.0 statistical package (SAS Institute Inc., Cary, $\mathrm{NC}$ ), and $\mathrm{P}<0.05$ was considered as statistically significant. Gene Ontology Generic GO slim in GeneSpring v.7.3.1 (Agilent Technologies) was used for the functional category classification (Student's $t$-test was used in GO).

\section{Authors' contributions}

MLC, CTY, JCC, CCH, SML, ISS, DIT, CMC, WPL, MYC, CKL, CTC, and DYL had made substantial contributions to acquisition of data and analysis and interpretation of data. MLC had been involved in designing experiments and drafting the manuscript. CTY had revised the paper critically for important intellectual content. All the authors had given final approval of the version to be published.

\section{Additional material}

\author{
Additional file 1 \\ List of differentially expressed genes potentially associated with pathogen- \\ esis of HCV core protein. \\ Click here for file \\ [http://www.biomedcentral.com/content/supplementary/1471- \\ 2164-9-109-S1.doc]
}

\section{Acknowledgements}

This work was supported by grants from National Science Council, Taiwan (Contracts Nos. NSC 93-23।4-B-I82A-148, 94-23।4-B-182A-185 and 953I I2-B-182A-002-) and Chang Gung Memorial Hospital, Taoyuan, Taiwan (Contract Nos. CMRPG 330I4, CMRPG 34034I, CMRP 800 and SMRPG35008I (ie. Terry Fox grant)).

\section{References}

I. Bacon BR, Farahvash MJ, Janney CG, Neuschwander-Tetri BA: Nonalcoholic steatohepatitis: an expanded clinical entity. Gastroenterology 1994, 107: 1 103-9.

2. Kim HJ, Kim HJ, Lee KE, Kim DJ, Kim SK, Ahn CW, Lim SK, Kim KR, Lee HC, Huh KB, Cha BS: Metabolic significance of nonalcoholic fatty liver disease in nonobese, nondiabetic adults. Arch Intern Med 2004, 164:2169-75.

3. Kainuma M, Fujimoto M, Sekiya N, Tsuneyama K, Cheng C, Takano Y, Terasawa K, Shimada $Y$ : Cholesterol-fed rabbit as a unique model of nonalcoholic, nonobese, non-insulin-resistant fatty liver disease with characteristic fibrosis. J Gastroenterol 2006, 4I:97I-80.

4. Qi NR, Wang J, Zidek V, Landa V, Mlejnek P, Kazdová L, Pravenec M, Kurtz TW: A new transgenic rat model of hepatic steatosis and the metabolic syndrome. Hypertension 2005, 45: I004-II.

5. Ramesh S, Sanyal AJ: Hepatitis $\mathbf{C}$ and nonalcoholic fatty liver disease. Semin Liver Dis 2004, 24:399-4I 3.

6. Chang ML, Chen JC, Yeh CT, Sheen IS, Tai DI, Chang MY, Chiu CT, Lin DY, Bissell DM: The topological and evolutional relationships between HCV core protein and hepatic lipid vesicles: studies in vitro and in conditionally transgenic mice. World J Gastroenterol 2007, 13:3472-3477.

7. Letteron P, Sutton A, Mansouri A, Fromenty B, Pessayre D: Inhibition of microsomal triglyceride transfer protein: another mechanism for drug-induced steatosis in mice. Hepatology 2003, 38: $133-40$

8. Barba G, Harper F, Harada T, Kohara M, Goulinet S, Matsuura Y, Eder G, Schaff Z, Chapman MJ, Miyamura T, Bréchot C: Hepatitis C virus core protein shows a cytoplasmic localization and associates to cellular lipid storage droplets. Proc Natl Acad Sci USA 1997, 94:1200-5.

9. Boulant S, Montserret R, Hope RG, Ratinier M, Targett-Adams P, Lavergne JP, Penin F, McLauchlan J: Structural determinants that target the hepatitis $C$ virus core protein to lipid droplets. J Biol Chem 2006, 28 I:22236-47.

10. Hope RG, McLauchlan J: Sequence motifs required for lipid droplet association and protein stability are unique to the hepatitis C virus core protein. J Gen Virol 2000, 81:1913-25.

II. McLauchlan J, Lemberg MK, Hope G, Martoglio B: Intramembrane proteolysis promotes trafficking of hepatitis $C$ virus core protein to lipid droplets. EMBO J 2002, $21: 3980-8$.

12. Moriya K, Yotsuyanagi H, Shintani Y, Fujie H, Ishibashi K, Matsuura $Y$, Miyamura T, Koike K: Hepatitis $\mathbf{C}$ virus core protein induces hepatic steatosis in transgenic mice. J Gen Virol 1997, 78:|527-3|.

13. Perlemuter G, Sabile A, Letteron P, Vona G, Topilco A, Chrétien Y, Koike K, Pessayre D, Chapman J, Barba G, Bréchot C: Hepatitis C virus core protein inhibits microsomal triglyceride transfer 
protein activity and very low density lipoprotein secretion: a model of viral-related steatosis. FASEB J 2002, 16:185-94.

14. Budhu A, Chen Y, Kim JW, Forgues M, Valerie K, Harris CC, Wang $X W$ : Induction of a unique gene expression profile in primary human hepatocytes by hepatitis C virus core, NS3 and NS5A proteins. Carcinogenesis 2007, 28: 1552-60.

15. Dou J, Liu P, Wang J, Zhang X: Effect of hepatitis C virus core shadow protein expressed in human hepatoma cell line on human gene expression profiles. J Gastroenterol Hepatol 2006, 21: $1794-800$.

16. Kubota N, Naganuma A, Kuge S: DNA microarray analysis of transcriptional responses of yeast cells to expression of core protein of hepatitis C virus. J Toxicol Sci 2007, 32:20I-4.

17. Moriya K, Fujie H, Shintani $Y$, Yotsuyanagi $H$, Tsutsumi T, Ishibashi $K$, Matsuura Y, Kimura S, Miyamura T, Koike K: The core protein of hepatitis $C$ virus induces hepatocellular carcinoma in transgenic mice. Nat Med 1998, 4:1065-7.

18. Moriya K, Nakagawa K, Santa T, Shintani Y, Fujie H, Miyoshi H, Tsutsumi T, Miyazawa T, Ishibashi K, Horie T, Imai K, Todoroki T, Kimura $\mathrm{S}$, Koike $\mathrm{K}$ : Oxidative stress in the absence of inflammation in a mouse model for hepatitis $\mathbf{C}$ virus-associated hepatocarcinogenesis. Cancer Res 200I, 61:4365-70.

19. Lan H, Rabaglia ME, Stoehr JP, Nadler ST, Schueler KL, Zou F, Yandell $B S$, Attie AD: Gene expression profiles of nondiabetic and diabetic obese mice suggest a role of hepatic lipogenic capacity in diabetes susceptibility. Diabetes 2003, 52:688-700.

20. Tan Y, Yoshida Y, Hughes DE, Costa RH: Increased expression of hepatocyte nuclear factor 6 stimulates hepatocyte proliferation during mouse liver regeneration. Gastroenterology 2006 130: 1283-300.

21. Ropolo A, Tomasini R, Grasso D, Dusetti NJ, Cerquetti MC, lovanna JL, Vaccaro MI: Cloning of IP I5, a pancreatitis-induced gene whose expression inhibits cell growth. Biochem Biophys Res Commun 2004, 3 I 9: 100|-9.

22. Ying J, Srivastava G, Hsieh WS, Gao Z, Murray P, Liao SK, Ambinder $R$, Tao $Q$ : The stress-responsive gene GADD45G is a functional tumor suppressor, with its response to environmental stresses frequently disrupted epigenetically in multiple tumors. Clin Cancer Res 2005, I I:6442-9.

23. Chiappini F, Barrier A, Saffroy R, Domart MC, Dagues N, Azoulay D, Sebagh M, Franc B, Chevalier S, Debuire B, Dudoit S, Lemoine A Exploration of global gene expression in human liver steatosis by high-density oligonucleotide microarray. Lab Invest 2006, 86: I54-65.

24. Sreekumar R, Rosado B, Rasmussen D, Charlton M: Hepatic gene expression in histologically progressive nonalcoholic steatohepatitis. Hepatology 2003, 38:244-5I.

25. Leclercq IA, Farrell GC, Field J, Bell DR, Gonzalez FJ, Robertson GR: CYP2EI and CYP4A as microsomal catalysts of lipid peroxides in murine nonalcoholic steatohepatitis. J Clin Invest 2000 , 105:1067-75.

26. Perlemuter G, Lettéron $P$, Carnot F, Zavala F, Pessayre D, Nalpas B, Bréchot C: Alcohol and hepatitis $C$ virus core protein additively increase lipid peroxidation and synergistically trigger hepatic cytokine expression in a transgenic mouse model. Hepatol 2003, 39:1020-7.

27. Sabile A, Perlemuter G, Bono F, Kohara K, Demaugre F, Kohara M, Matsuura $Y$, Miyamura T, Bréchot C, Barba G: Hepatitis C virus core protein binds to apolipoprotein All and its secretion is modulated by fibrates. Hepatology 1999, 30:1064-76.

28. Meunier JC, Engle RE, Faulk K, Zhao M, Bartosch B, Alter H, Emerson SU, Cosset FL, Purcell RH, Bukh J: Evidence for cross-genotype neutralization of hepatitis $C$ virus pseudo-particles and enhancement of infectivity by apolipoprotein $\mathrm{Cl}$. Proc Natl Acad Sci USA 2005, 102:4560-5.

29. Dongol B, Shah Y, Kim I, Gonzalez FJ, Hunt MC: The acyl-CoA thioesterase I (AcotI) is regulated by the peroxisome proliferator-activated receptor alpha and hepatocyte nuclear factor 4 alpha via a distal response element in the promotor. Lipid Res 2007, 48: I78I-9I.

30. Yamada J, Kuramochi Y, Takoda Y, Takagi M, Suga T: Hepatic induction of mitochondrial and cytosolic acyl-coenzyme a hydrolases/thioesterases in rats under conditions of diabetes and fasting. Metabolism 2003, 52:1527-9.

31. Yin HQ, Kim M, Kim JH, Kong G, Lee MO, Kang KS, Yoon BI, Kim $\mathrm{HL}$, Lee BH: Hepatic gene expression profiling and lipid home- ostasis in mice exposed to steatogenic drug, tetracycline. Toxicol Sci 2006, 94:206-16.

32. Su AI, Pezacki JP, Wodicka L, Brideau AD, Supekova L, Thimme R, Wieland S, Bukh J, Purcell RH, Schultz PG, Chisari FV: Genomic analysis of the host response to hepatitis $C$ virus infection. Proc Natl Acad Sci USA 2002, 99: I5669-74.

33. Waris G, Felmlee DJ, Negro F, Siddiqui A: Hepatitis C virus induces the proteolytic cleavage of sterol regulatory element binding proteins (SREBPs) and stimulates the phosphorylation of SREBPs via oxidative stress. J Virol 2007, 8I:8I22-30

34. Moriishi $\mathrm{K}$, Mochizuki R, Moriya $\mathrm{K}$, Miyamoto $\mathrm{H}$, Mori $\mathrm{Y}$, Abe $\mathrm{T}$, Murata S, Tanaka K, Miyamura T, Suzuki T, Koike K, Matsuura Y: Critical role of PA28gamma in hepatitis C virus-associated steatogenesis and hepatocarcinogenesis. Proc Natl Acad Sci USA 2007, 104:1661-6.

35. Chmurzynska A: The multigene family of fatty acid-binding proteins (FABPs): function, structure and polymorphism. J Appl Genet 2006, 47:39-48.

36. Duplus $E$, Forest $C$ : Is there a single mechanism for fatty acid regulation of gene transcription? Biochem Pharmacol 2002, 64:893-901.

37. Spann NJ, Kang S, Li AC, Chen AZ, Newberry EP, Davidson NO, Hui ST, Davis RA: Coordinate transcriptional repression of liver fatty acid-binding protein and microsomal triglyceride transfer protein blocks hepatic very low density lipoprotein secretion without hepatosteatosis. J Biol Chem 2006, 28 I:33066-77.

38. Perlemuter G, Sabile A, Letteron P, Vona G, Topilco A, Chrétien Y, Koike K, Pessayre D, Chapman J, Barba G, Bréchot C: Hepatitis C virus core protein inhibits microsomal triglyceride transfer protein activity and very low density lipoprotein secretion: a model of viral-related steatosis. FASEB J 2002, 16: 185-94.

39. Kistner A, Gossen M, Zimmermann F, Jerecic J, Ullmer C, Lübbert H, Bujard $\mathrm{H}$ : Doxycycline-mediated quantitative and tissue-specific control of gene expression in transgenic mice. Proc Nat Acad Sci USA 1996, 93: 10933-8.

40. Wang R, Ferrell LD, Faouzi S, Maher J], Bishop JM: Activation of the Met receptor by cell attachment induces and sustains hepatocellular carcinomas in transgenic mice. J Cell Biol 200I, I53:1023-34.

4I. Staudacher T, Pech B, Tappe M, Gross G, Muhlbauer B, Luippold G: Arterial blood pressure and renal sodium excretion in dopamine D3 receptor knockout mice. Hypertens Res 2007, 30:93-101.

42. Peng X, Wood CL, Blalock EM, Chen KC, Landfield PW, Stromberg AJ: Statistical implications of pooling RNA samples for microarray experiments. BMC Bioinformatics 2003, 4:26.

43. Kim SY, Lee JW, Bae JS: Effect of data normalization on fuzzy clustering of DNA microarray data. BMC Bioinformatics 2006, 7:134.

44. Tusher VG, Tibshirani R, Chu G: Significance analysis of microarrays applied to the ionizing radiation response. Proc Natl Acad Sci USA 200I, 98:5II6-2I.

45. ArrayXPath [http://www.snubi.org/software/ArrayXPath/]

Publish with Biomed Central and every scientist can read your work free of charge

"BioMed Central will be the most significant development for disseminating the results of biomedical research in our lifetime. "

Sir Paul Nurse, Cancer Research UK

Your research papers will be:

- available free of charge to the entire biomedical community

- peer reviewed and published immediately upon acceptance

- cited in PubMed and archived on PubMed Central

- yours - you keep the copyright
BioMedcentral 